\title{
Revisitando as Críticas Pós-Keynesianas à Nova Síntese Neoclássica: Questões de Política Monetária
}

\section{Revisiting the Post-Keynesian Critics of New Neoclassical Synthesis:Monetary Policy Questions}

Ricardo Ramalhete Moreira*

Resumo: O artigo aborda algumas críticas pós-keynesianas recentes à chamada Nova Síntese Neoclássica, baseando-se em respostas a três questões teóricas relativas: a) aos limites do crescimento econômico de longo prazo; b) à determinação da taxa de inflação; c) aos objetivos que norteiam a condução ideal da política monetária. Trata-se de questões teóricas que inevitavelmente possuem influência na prática da política monetária no mundo contemporâneo.

Palavras-chave: Política monetária. Pós-keynesianos. Nova Síntese Neoclássica.

Abstract: The article presents some recent post-keynesian comments on the New Neoclassical Synthesis, by means of answers to three theoretic questions regarding: a) the constraints to the long term output growth; b) the inflation rate determination; c) the main goals that lead the monetary policy to an optimal conduction. These questions inevitably have effects on the contemporaneous monetary policy conduction.

Keywords: Monetary policy. Post-keynesian. New Neoclassical Synthesis.

JEL Classification: E52; E12; E13.

\section{Introdução}

A prática da política monetária no mundo é inevitavelmente influenciada pelo status quo do pensamento econômico, no que respeita a questões sobre os limites ao crescimento econômico, os determinantes inflacionários e os objetivos de política no curto e no longo prazo. Ainda que o uso dos instrumentos de política monetária seja também afetado pela experiência tácita e pelos julgamentos

Professor no Programa de Pós-Graduação em Economia da Universidade Federal do Espírito Santo (UFES). E-mail: ramalhete.s@gmail.com 
subjetivos das autoridades monetárias, a contextualização das decisões dos Bancos Centrais está grandemente apoiada na natureza e na evolução da teoria de política monetária que predomina em cada momento.

É com base nessa premissa que se torna fundamental uma clara compreensão de quais são as hipóteses e os pressupostos que sustentam a forma de se pensar a política monetária por parte das autoridades dos Bancos Centrais contemporâneos. E para tanto, faz-se necessário adentrar na corrente de pensamento que nos dias atuais molda o debate em torno das questões relevantes. Neste caso, em especial no que respeita à política monetária, a chamada Nova Síntese Neoclássica - uma espécie de junção de elementos dos Novos Clássicos da década de 70 com elementos da escola Novo-Keynesiana dos anos 80 e 90 - é a corrente de pensamento em voga, pelo menos no que concerne à prática de resposta dos Bancos Centrais no mundo, nesse início de século XXI.

O presente trabalho tem como objetivo abordar os principais argumentos e ideias dessa corrente hegemônica, contrastando-os com críticas e formulações emitidas por autores pós-keynesianos. Neste sentido, o artigo também representa um esforço de comparação teórica a respeito de questões relativas à política monetária, em especial: a) quais são os determinantes da produção e do crescimento econômico no longo prazo? b) como a inflação é determinada, ou seja, quais são os fatores que afetam sistematicamente a variação de preços na economia? c) com base em quais objetivos e reações a política monetária deve ser conduzida?

Acredita-se que esses itens representam um pano de fundo na discussão sobre uma série de assuntos mais específicos nos dias atuais, como por exemplo, os relativos ao ajuste das taxas básicas de juros, à importância de credibilidade dos Bancos Centrais, às respostas face aos choques inflacionários variados, ao regime de metas de inflação, etc.

O trabalho segue a seguinte estrutura analítica: na seção 2 serão analisados os elementos teóricos que explicam os limites ao produto e ao crescimento econômico de longo prazo: na escola Nova Síntese esse tema parte daquilo que se chama por hipótese da taxa natural, ao passo que nos pós-keynesianos o tema é tratado basicamente por meio da ideia de endogenia do produto potencial pelo lado da demanda; na seção 3, verifica-se que o fenômeno inflacionário é explicado na Nova Síntese sobretudo como sendo um caso de demanda, ao afetar custos marginais no processo produtivo; já os pós-keynesianos darão fundamental importância aos componentes de custos e de barganhas sociais como principais fatores de condicionamento da inflação. A seção 4, por sua vez, lida com as questões que norteiam os objetivos de política monetária e que condicionam o uso dos instrumentos de política monetária, em ambas as escolas aqui estudadas. 


\section{Onde estão os limites ao produto e ao crescimento econômico de longo prazo?}

\subsection{A hipótese da taxa natural na Nova Síntese}

Nos modelos da Nova Síntese Neoclássica, concebe-se o nível de produto potencial, assim como a taxa de crescimento econômico de longo prazo, como fenômenos determinados pelo lado da oferta. Trata-se da adoção da hipótese da taxa natural: os níveis de produto potencial e taxa de juros de equilíbrio (taxa natural de juros) dependem apenas de fatores reais, tais como produtividade geral dos fatores, preferências intertemporais dos agentes e estoque de capital e trabalho. Isto ocorre porque a Nova Síntese pode ser compreendida como a junção de duas tradições de pensamento e premissas teóricas: a tradição novo-keynesiana e a tradição dos ciclos reais de negócios (GOODFRIEND; KING, 1997). Pelo lado novo-keynesiano, os modelos da Nova Síntese adotam as hipóteses de competição monopolística ou imperfeita e rigidez de preços; pelo lado dos ciclos reais, adota-se as hipóteses de otimização intertemporal e expectativas racionais com flexibilidade perfeita de preços. Trata-se de uma dicotomia metodológica no que diz respeito aos prazos de análise: considera-se, nessa abordagem, o curto prazo como o prazo em que os ajustamentos de preços não são feitos na medida suficiente para responderem integralmente aos choques; isto cria uma resposta via quantidades. Por outro lado, passado o prazo temporal necessário para a eliminação dos fatores de inércia e rigidezes, os preços são ajustados integralmente às variações da demanda agregada, e neste caso não há resposta via quantidades. Tem-se aqui uma espécie de equilíbrio walrasiano, em que apenas os preços são ajustados a fim de que seja mantida uma igualdade entre produto potencial e produto efetivo. Assim, enquanto no curto prazo prevalece o teor novo-keynesiano, tornando o nível de produto real correlacionado com movimentos da demanda agregada, no longo prazo os modelos da Nova Síntese apresentam teor novo-clássico, assumindo neutralidade monetária e ausência de correlação entre demanda e produto real.

O modelo básico de Clarida, Galí e Gertler (1999), por exemplo, parte de duas equações: uma IS e uma curva de Phillips com componente expectacional ou forward-looking ${ }^{1}$. Trata-se do que os autores chamam de um modelo dinâmico de equilíbrio geral, com moeda e rigidez transitória de preços. Essa configuração tem

1 Embora no curto prazo o modelo de Clarida, Galí e Gertler (1999) apresente traços marcantes do pensamento novo-keynesiano, devido às rigidezes de preços e salários e à concorrência monopolística, no longo prazo, com flexibilidade perfeita, o modelo também apresenta traços dos modelos de ciclos reais de negócios, dentre os quais a neutralidade monetária e a inexistência de trade-off entre inflação e desemprego, ou seja, a conhecida verticalização da curva de Phillips. 
se tornado frequente na literatura recente mainstream para a avaliação da política monetária, como se pode deduzir pelos trabalhos de Goodfriend e King (1997), McCallum e Nelson (1999) e Walsh (2003).

Os modelos e o pensamento da Nova Síntese aceitam a existência de movimentos nas taxas naturais, ou seja, no nível de produto potencial e de taxa natural de juros. No entanto, tais variações são determinadas basicamente por choques de produtividade e de preferências (GALÍ; GERTLER, 2007). Logo, embora se possa falar em produto potencial endógeno, este é endógeno tão somente pelo lado da oferta, por mudanças em fatores não correlacionados com o âmbito da demanda efetiva ou monetária. Mesmo a influência que o investimento possa ter sobre o produto potencial, via acumulação de capital, é vista como uma resposta à chamada substituição intertemporal do consumo: vê-se o investimento e sua dinâmica como dependentes de decisões de não consumo corrente, ou seja, de decisões de poupança; neste caso, os investimentos privados não são o resultado de decisões autônomas de formação de capital fixo na economia, mas sim de sinais de mercado, via taxa de juros, interpretados como procura por consumo futuro. $\mathrm{O}$ investimento seria, em última instância, determinado pela poupança; logo, a expansão do estoque de capital seria resultado das forças de oferta.

Uma questão importante a se levar em conta é que, para o mainstream, há apenas um único nível de produto potencial a ser respeitado pela autoridade monetária; em outras palavras, há um único nível de limite físico de produção, que se for respeitado não induz processos de aceleração ou desaceleração de preços na economia. Logo, enquanto a meta de inflação seria uma variável de escolha da autoridade monetária, o produto potencial seria uma variável de estado, imposta exogenamente pelas condições de oferta da economia e fora de controle da política monetária. Dificuldades poderiam advir tão somente no que diz respeito à estimação ou mensuração do valor do produto potencial. Assim, o produto potencial é concebido como uma restrição física, objetiva e não ligada a decisões ou expectativas empresariais. Qualquer nível de produção vigente que seja diferente desse nível potencial único implicaria ou em aumento ou em redução da taxa inflacionária. Semelhantemente, quaisquer taxas de crescimento do produto que sejam diferentes da taxa potencial de crescimento da economia - dada pela taxa de poupança, pela dinâmica da produtividade e pelo crescimento populacional implicariam necessariamente pressões inflacionárias ou deflacionárias pelo lado da demanda.

Além de pressões sobre a taxa de inflação, diferenças entre produto potencial e produto efetivo, ou entre taxa de crescimento efetiva e taxa potencial, não gerariam nenhum efeito sobre as condições de produção da economia, ou seja, não teriam qualquer impacto sobre o produto potencial da economia ao longo 
do tempo. Isto decorre da hipótese da taxa natural e de neutralidade da moeda no longo prazo. Assim, as pressões inflacionárias não seriam amortecidas por uma eventual redução endógena do gap do produto, mas apenas como efeito de respostas da política monetária via variações nas taxas reais de juros. A inexistência de correlação entre produto potencial e as flutuações de curto prazo no gap do produto (diferença entre produto efetivo e potencial) pode ser interpretada como uma ausência de histerese e path-dependence. Seja a seguinte função produto potencial, tal como posta em Moreira (2009):

$$
\mathrm{YPt}^{\mathrm{P}}=\mathrm{YP} \mathrm{t}-1+\mathrm{v}\left(\mathrm{Yt}-2-\mathrm{YPt}^{\mathrm{P}}-2\right)+\delta \mathrm{t}
$$

Em que $Y^{p t}$ é o produto potencial em t; $Y^{p t-1}$ o produto potencial em t-1; $v$ um coeficiente de sensibilidade maior ou igual a zero; (Yt-2 - Y $\left.{ }^{p}-2\right)$ o gap do produto em t-2; e $\delta t$ um choque de produtividade em t com propriedades estatísticas bem definidas. A equação acima estabelece um processo de histerese: uma correlação entre o gap do produto em t-2 e o produto potencial em t para um $v$ maior que zero. No entanto, a Nova Síntese pode ser associada ao caso especial em que se concebe $v$ como igual a zero, ou seja, ao caso em que não se permite correlações entre os gaps do produto e o produto potencial ao longo do tempo. Neste caso, as flutuações de curto prazo não determinam as posições estacionárias de longo prazo, e modificações de produto potencial só podem ser o resultado de choques de produtividade ( $\delta \mathrm{t})$, tal como em Galí e Gertler (2007).

Dados os fatores de inércia na economia, um gap inicial do produto devido, por exemplo, a um choque de demanda, resultaria em uma auto-propagação e em pressões inflacionárias persistentes, ainda que tais desequilíbrios possam ser gradualmente amortecidos. Neste caso, uma política monetária guiada por um regime de metas de inflação (Inflation Targeting) responderia ao choque de demanda por meio de ajustes nas taxas reais de juros, no sentido de criar uma variação da atividade econômica e uma convergência da inflação futura para a meta de inflação, dentro do prazo estipulado pelas autoridades. Tal política seria sugerida porque, na Nova Síntese, supõe-se que essa resposta de taxa real de juros estabilize tanto a inflação quanto o produto ao longo do tempo, sem qualquer custo ou perda para a dinâmica produtiva de longo prazo (MOREIRA, 2009).

\subsection{A crítica pós-keynesiana: endogenia do produto potencial e efeitos reais de longo prazo}

O ponto de partida da argumentação pós-keynesiana, no que se refere à questão do chamado produto potencial, da taxa natural de desemprego (NAIRU - no português, taxa de desemprego de inflação não aceleracionista) e do crescimento de longo prazo, é que essas variáveis são sujeitas a processos de trajetória 
dependente (path-dependence) e histerese, sob um contexto em que prevalece a não neutralidade da moeda, seja no curto prazo, seja no longo prazo ${ }^{2}$.

Sob essa perspectiva, a expansão da capacidade produtiva de uma economia depende basicamente das decisões de formação bruta de capital fixo, as quais, por sua vez, estão diretamente associadas às observações dos empresários a respeito das condições de mercado. Uma série de trabalhos tenta formalizar teoricamente o papel do efeito acelerador na determinação dos investimentos privados. Alguns trabalhos podem ser representativos de uma tendência, na literatura heterodoxa, para a consideração do efeito acelerador na dinâmica macroeconômica. Lopéz (1986) apresenta a seguinte forma de determinação dos investimentos empresariais em uma economia capitalista, seguindo a tradição de Kalecki (1954):

$$
\mathrm{D}=\mathrm{eE}+\mathrm{r}\left(\mathrm{g}-\mathrm{g}^{*}\right)+\mathrm{B}(\mathrm{t})
$$

Em que D são as novas decisões de investimento, E são poupanças empresariais, g é a taxa de lucro auferida no período passado, g* é a taxa de lucro considerada normal e $\mathrm{B}(\mathrm{t})$ é o progresso técnico, que é função do tempo. O parâmetro e é menor que 1 e indica a proporção da poupança empresarial que é investida; r mede a sensibilidade das inversões em relação ao gap da taxa de lucro. O efeito acelerador está presente na função acima por meio do componente de fluxo $\mathrm{r}\left(\mathrm{g}-\mathrm{g}^{*}\right)$, que depende diretamente da dinâmica da demanda, das vendas e da produção. É interessante notar a semelhança dessa função acima com a utilizada em Oreiro (2001):

$$
\mathrm{g}_{\mathrm{k}}=\mathrm{f}+\mathrm{h}[\mathrm{u}-\mathrm{k}]+\gamma_{1} \Omega-\gamma_{2} \mathrm{r}
$$

Sendo $\mathrm{g}_{\mathrm{k}}$ a taxa de crescimento do estoque de capital, f o animal spirits dos empresários, $u$ o grau efetivo de utilização do estoque de capital, k o grau normal de utilização, $\Omega$ a taxa esperada de lucro e $r$ a taxa real de juros. Todos os parâmetros são positivos. Neste caso, a taxa real de juros pode ter seus efeitos neutralizados sobre os investimentos e a formação de capital, dependendo do comportamento dos demais componentes da função. Se por um lado a dinâmica dos investimentos é responsável pela trajetória cíclica da renda e do produto, por outro lado a dinâmica da produção $(\mathrm{u}-\mathrm{k})$, pelo acelerador, é responsável pelos novos investimentos. Trata-se de uma abordagem muito próxima à utilizada em Oreiro e Ono (2004). Neste trabalho, os autores seguem a tradição de Kaldor (1955), Robinson (1962), Pasinetti (1962) e Bhaduri e Marglin (1990), supondo a seguinte determinação da taxa de crescimento desejada do capital:

$$
\mathrm{I} / \mathrm{K}=\alpha_{0}+\alpha_{1} \mathrm{~m}+\alpha_{2} \mathrm{u} \sigma, \text { onde }: \alpha_{0}>0, \alpha_{1}>0, \alpha_{2}>0
$$

Sendo $\mathrm{I} / \mathrm{K}$ a taxa de crescimento desejada do capital (I o investimento e $\mathrm{K}$ o estoque de capital). Em que $\alpha_{0}$ é um componente autônomo, $m$ a participação

$2 \quad$ Neste artigo, parte-se da ideia de que os argumentos e os fundamentos a respeito da não-neutralidade monetária estejam sendo já conhecidas pelo leitor. Para uma discussão sobre o tema, conferir os trabalhos de Fernando Cardim de Carvalho e Paul Davidson sobre o tema. 
dos lucros na renda, $u$ a utilização do estoque de capital e $\sigma$ a relação produto/ capital, que dá uma medida de produtividade do capital. A função acima, da mesma forma que em Lopéz (1986) e Oreiro (2001), concede peso ao componente de renda e produção na determinação dos investimentos, explicitando o efeito acelerador. Outro trabalho que se alinha nessa tendência da literatura heterodoxa é Lima e Meirelles (2007). Seguindo Rowthorn (1981), Dutt (1990), Kalecki (1971), Robinson (1962) e Dutt (1994), os autores especificam a seguinte função taxa de investimento desejada:

$$
\mathrm{g}^{\mathrm{d}}=\alpha+\beta \mathrm{r}-\gamma \mathrm{i}
$$

Sendo gd a taxa desejada de investimento, ou a formação desejada de capital, $r$ a taxa de lucro sobre o capital existente e i a taxa de juros. Os parâmetros $\alpha$, $\beta$ e $\gamma$ são positivos. A taxa de lucro depende dos gastos na tradição kaleckiana; e os investimentos dependem da taxa de lucro, ou seja, trata-se da interação multiplicador/acelerador. Por outro lado, os componentes autônomos nessas funções mostram que a renda, embora estimule novos investimentos, não representa um limite para os mesmos, já que elementos como expectativas, crédito e animal spirits podem potencializar ou contrair as inversões, independentemente do que ocorra com a renda e produção correntes. Todos esses trabalhos ressaltam a ideia de que a demanda efetiva está determinando a dinâmica do produto, inclusive no longo prazo, por meio da endogenia do produto potencial ou da taxa potencial de crescimento. Rompe-se com a hipótese ortodoxa de que os valores desejados, normais ou potenciais são valores de equilíbrio determinados pelo lado da oferta. Além de móveis e provavelmente instáveis, esses valores são dependentes do comportamento dos gastos, em particular da trajetória dos investimentos privados. Uma última formalização poderia ser útil com vistas à questão da endogenia do produto potencial pelo lado da demanda. Seja a dinâmica dos investimentos dada por:

$$
\mathrm{I}=\mathrm{I}^{\mathrm{d}}+\mathrm{a}\left(\mathrm{Y}_{-1}-\mathrm{Yp}_{-1}\right)-\mathrm{b}\left(\mathrm{R}_{-1}-\mathrm{Rn}\right)
$$

Em que I são os investimentos privados em formação bruta de capital fixo, $\mathrm{I}^{\mathrm{d}}$ os investimentos desejados, $\mathrm{Y}_{-1}$ o produto efetivo no período passado, $\mathrm{Yp}_{-1}$ o produto potencial em t-1, $R_{-1}$ a taxa real de juros no período passado e $\mathrm{Rn}$ a taxa natural de juros (considerada uma tendência histórica e condicional, e não um atrator exógeno); $a$ e $b$ são positivos. Seja ainda:

$$
\mathrm{Yp}-\mathrm{Yp}_{-1}=\mathrm{I}_{-1}+\mathrm{H}
$$

Em (7), a variação do produto potencial depende dos investimentos em t-1 e de um componente de oferta $(\mathrm{H})$, que expressa o comportamento da produtividade e do crescimento populacional. Substituindo a função investimento (6) nessa equação acima (7), e isolando Yp, tem-se:

$$
\mathrm{Yp}=\mathrm{Yp}_{-1}+\mathrm{I}^{\mathrm{d}}+\mathrm{a}\left(\mathrm{Y}_{-2}-\mathrm{Yp}_{-2}\right)-\mathrm{b}\left(\mathrm{R}_{-2}-\mathrm{Rn}\right)+\mathrm{H}
$$


Observa-se que o produto potencial é considerado endógeno pelo lado da demanda, ainda que se considere um componente determinado pelo lado da oferta $(\mathrm{H})$. Os investimentos desejados (autônomos) e os induzidos, que dependem da renda, estão determinando a dinâmica da capacidade produtiva. Verifica-se também uma influência da política monetária sobre o produto potencial, com defasagem de dois períodos, o que resulta na ideia de não neutralidade da política monetária no longo prazo. A política monetária não afeta apenas a demanda e a produção no curto prazo; afeta também as decisões de investimento e a dinâmica temporal da formação bruta de capital fixo no longo prazo.

Ademais, Rowthorn (1999) e Sawyer (2002) têm introduzido a ideia de acumulação de capital endógena e uma espécie de NAIRU endógena, sob uma perspectiva pós-keynesiana e pós-kaleckiana, considerando as implicações para a dinâmica econômica. Rowthorn (1999), motivado por um desejo de saber por que a taxa de desemprego na Europa tem se mantido elevada no pós-choque dos 70, propôs um modelo no qual os investimentos privados são endógenos em uma variedade de formas, tais como pelos lucros reais e pelas taxas de juros. Sua principal conclusão é a de que "[...] a permanent reduction in the real interest rate leads to only a temporary acceleration in economic growth but a permanent fall in unemployment." (ROWTHORN, 1999, p. 423), o que rompe com os resultados do mainstream.

Na mesma linha, Sawyer (2002) dá ênfase ao papel da demanda agregada na determinação da dinâmica do estoque de capital e do emprego valendo-se do conceito de NAIRU. Assumindo pressupostos não convencionais, Sawyer (2002) argumenta que existem relações de longo prazo entre inflação e desemprego, e entre este último e a acumulação de capital. O autor busca demonstrar que uma redução da NAIRU pode ser alcançada por meio de um aumento sustentado da demanda agregada para estimular os investimentos; além disto, critica as ideias de que uma redução da inflação, via elevação da taxa de juros, pode ser feita sem qualquer custo em termos reais e a ideia de que não há trade-off de longo prazo entre inflação e desemprego. Em adição, Lavoie (2006) e Fontana e Palacio-Vera (2007), entre outros, representam interessantes contribuições ao tema do produto potencial endógeno ou da taxa natural endógena de crescimento. Lavoie (2006), particularmente, apresenta uma "emenda" à Nova Síntese ao levar em conta que "The natural rate of growth is ultimately endogenous to the demand-determined actual rate of growth" (SETTERFIELD, 2002, p. 5).

Lavoie (2006) argumenta que, como León-Lesdema e Thirlwall (2002) têm mostrado em um estudo empírico para 15 países ao longo do pós-guerra, quando a taxa observada de crescimento da demanda diverge da taxa natural de crescimento do produto é criada uma mudança nesta última que a faz convergir para aquela primeira. Essa ideia permite "[...] the possibility of multiple equilibria, that 
make long-run supply forces dependent on short run disequilibrium adjustment paths induced by effective demand." (LAVOIE, 2006, p. 177); que é compatível com o pressuposto adotado por León-Lesdema e Thirlwall (2002, p. 452): “[...] growth creates its own resources in the form of increased labour force availability and higher productivity of the labour force".

Ademais, Fontana e Palacio-Vera (2007) estudam as implicações de diferentes pressupostos, tais como de raiz unitária, histerese e de equilíbrios múltiplos, junto a modelos de crescimento pela demanda, para a análise de dinâmica econômica e de estratégia de política monetária; os resultados encontrados mostram que:

[...] monetary policy does have long-run effects on output and employment [...] the demand side of the market does matter in both the short and the long run [...] flexible' opportunistic approach which not only seeks to stabilize output in the short run and achieve price stability in the long run but that also makes an active contribution to the growth of output and employment (FONTANA; PALACIO-VERA, 2007, p. 294)

Em estudo recente aplicado à economia brasileira, e com base em estimativas de produto potencial baseadas no filtro estatístico de Hodrick-Prescott ${ }^{3}$ - amplamente utilizado em estudos macroeconômicos aplicados -, Barbosa-Filho (2009, p. 53-54) afirma que:

A análise do caso brasileiro nos últimos anos confirmou exatamente esta proposição, isto é, a aceleração do crescimento econômico ocorrida nos últimos anos levou a uma revisão das estimativas do PIB potencial brasileiro para cima e, consequentemente, a uma revisão das estimativas de hiato do produto para baixo.

O autor adverte sobre as implicações dessa endogeneidade das estimativas do produto potencial para a prática da política monetária: as decisões do BC devem ser orientadas por projeções de diferentes cenários de crescimento, uma vez estes possuem impacto na avaliação da atividade econômica corrente - via reestimativas de produto potencial - e, portanto, na própria política monetária; além disto, as decisões de política têm impactos nas estimativas futuras de produto potencial, por meio de seus efeitos sobre a dinâmica produtiva:

3 O filtro Hodrick-Prescott (HP) é um filtro estatístico univariado que decompõe uma determinada série temporal em dois componentes: um componente de tendência variável suavizada e um componente de ciclo. Barbosa-Filho (2009) também faz testes para o produto potencial da economia brasileira através de um filtro HP com função de produção agregada, que nada mais é do que uma média móvel ponderada de três variáveis: taxa de emprego, taxa de utilização da capacidade produtiva e PIB real. No entanto, as conclusões do trabalho, quanto à endogeneidade das estimativas do produto potencial e à sua variabilidade ao final da amostra, são mantidas independentemente da inclusão ou não de uma função de produção. 
Em outras palavras, como o desempenho da economia no futuro próximo afetará a estimativa do hiato do produto para o período atual, é necessário incluir cenários alternativos de crescimento na avaliação do nível de atividade da economia. Caso a economia cresça mais rapidamente no futuro, o que hoje pode parecer um nível de atividade superaquecido talvez se revele mais tarde um nível de atividade neutro ou até sub-aquecido [...] uma política monetária que desacelera o crescimento do PIB para combater pressões inflacionárias de demanda tende a reduzir a taxa de crescimento do produto potencial. (BARBOSA-FILHO, 2009, p. 54).

\section{Quais são os determinantes relevantes da taxa de inflação?}

\subsection{A visão da Nova Síntese: hiato do produto, custos marginais, mark-ups e inflação}

No que diz respeito ao processo de determinação inflacionária, a Nova Síntese basicamente concebe o mesmo como sendo devido a pressões pelo lado da demanda, o que estaria forçando variações dos custos marginais e dos mark-ups, e desta forma variações dos preços desejados e observados na economia. Um modelo que expressa essa visão está formalizado em Goodfriend e King (1997), através de um instrumental matemático árduo e rigoroso, porém inteligível. Com o propósito de evitar a exaustão formal presente naquele instrumental, elaborase uma formalização alternativa, de certa forma simples, com o único intuito de enunciar os principais fundamentos da Nova Síntese, sugeridos por Goodfriend e King (1997), clara e objetivamente, no que se refere ao fenômeno inflacionário. Seja o comportamento de ajuste dos preços, por parte das firmas:

$$
\mathrm{P}^{*} \mathrm{t}=\mathrm{E}[\mathrm{Pt}+1]+\mathrm{E}[\psi \mathrm{t}+1-\psi]
$$

Em que $P^{*} t$ é o preço desejado pela média das firmas no período $t$, em contexto de competição imperfeita e rigidez de preços. Esse preço depende da esperança matemática para o nível geral de preços em $t+1(E[\mathrm{Pt}+1])$ e da esperança para o desvio do custo marginal real em $\mathrm{t}+1$ em relação ao custo marginal real de equilíbrio $(E[\psi t+1-\psi])$, sendo $\psi$ o custo marginal real de steady-state (equilíbrio de longo prazo). Seja o nível geral de preços em $t$ dado por:

$$
\mathrm{Pt}=\omega \mathrm{P}^{*} \mathrm{t}
$$

Em que Pt é o nível geral de preços observado em t, o qual pode diferir, por definição, de $\mathrm{P}^{*}$ t, porém guardando uma correlação estável com este último por meio de uma constante positiva $\omega(0 \leq \omega \leq 1)$. Pela equação (10), pode-se afirmar que:

$$
\mathrm{E}[\mathrm{Pt}+1]=\omega \mathrm{E}\left[\mathrm{P}^{*} \mathrm{t}+1\right]
$$


Seja ainda:

$$
(\psi t-\psi)=-(\mu \mathrm{t}-\mu)
$$

A expressão (12) mostra a relação recíproca entre o desvio do custo marginal real e o desvio do mark-up médio, em contexto de rigidez de preços, sendo $\mu$ o mark-up médio de steady-state (equilíbrio de longo prazo). A partir das expressões (11) e (12), pode-se rearranjar (9) da seguinte forma:

$$
\omega E\left[P^{*} \mathrm{t}+1\right]-\mathrm{Pt}^{*}=\mathrm{E}[\mu \mathrm{t}+1-\mu]
$$

Em (13), verifica-se que, dado $\omega$, há uma correlação positiva entre a variação esperada do preço desejado e a variação esperada do mark-up médio. Ademais, pela perspectiva da Nova Síntese, a condição de política monetária neutra é a de que haja estabilidade do mark-up médio ao nível de steady-state, em todos os períodos do tempo, tal que:

$$
\mathrm{E}[\mu \mathrm{t}+1-\mu]=\mu \mathrm{t}-\mu=\mu \mathrm{t}-1-\mu=\ldots=0
$$

Logo, satisfeita a condição (14), e a partir de (13), tem-se o seguinte resultado da política monetária neutra:

$$
\omega E[P * t+1]-P t^{*}=0
$$

O que implica:

$$
\omega \mathrm{E}[\mathrm{P} * \mathrm{t}+1]=\mathrm{Pt}^{*}
$$

Uma solução possível é $\mathrm{Pt}^{*}=\mathrm{E}\left[\mathrm{P}^{*} \mathrm{t}+1\right]$, e $\omega=1$. Trata-se de uma situação idealizada, em que os agentes não esperam mudança dos preços desejados, dado que a política monetária está comprometida com a estabilização do markup médio em torno de seu valor de longo-prazo. Isto é compatível com a situação na qual as expectativas de inflação e gap do produto para $t+1$ são zero, respectivamente:

$$
\mathrm{E}[\pi \mathrm{t}+1]=\mathrm{E}[\mathrm{yt}+1]=0
$$

Por outro lado, caso $\omega<1$, tem-se que $\mathrm{E}\left[\mathrm{P}^{*} \mathrm{t}+1\right]>\mathrm{Pt} *$. No entanto, havendo estabilidade do valor de $\omega$, a variação dos preços segue um comportamento estável, ou seja, a inflação é estabilizada em torno de uma meta. Logo, tem-se a condição de gap do produto igual a zero e inflação equivalente à meta adotada.

$$
\mathrm{E}[\pi \mathrm{t}+1]=\pi^{\mathrm{T}} \text { e } \mathrm{E}[\mathrm{yt}+1]=0 \text {, sendo } \pi^{\mathrm{T}} \text { a meta de inflação }
$$

Observa-se por esse modelo que a Nova Síntese vê a inflação como um fenômeno de repasse de variações nos preços desejados pelas firmas para os preços observados, preços estes que podem se elevar seja pela simples expectativa de maiores preços futuros, seja por pressões de demanda que se expressam pelas elevações nos custos marginais e reduções nos mark-ups. Havendo inexistência de desequilíbrios no mercado de bens, haveria apenas uma inflação residual condicionada à credibilidade de política monetária e à meta anunciada de inflação $\left(\pi^{\mathrm{T}}\right)$. 


\subsection{Alteração da curva de Phillips e inflação estruturalista nos pós-keynesianos}

Kriesler e Lavoie (2007) buscam desenvolver uma especificação pós-keynesiana da curva de Phillips. A partir de Setterfield (2005), Kriesler e Lavoie (2007) apresentam inicialmente os principais aspectos da Nova Síntese Neoclássica, por meio de um modelo analítico simples, para depois incorporarem no mesmo alguns elementos heterodoxos. Inicialmente, os autores especificam uma curva de Phillips que seria válida, a seu ver, tanto para a versão monetarista de Friedman quanto para os modelos da Nova Síntese. Tem-se:

$$
\Delta \pi=\beta 1(\mathrm{u}-\mathrm{un})+\varepsilon 1
$$

Em que $\Delta \pi$ é a variação da inflação, $u$ é o nível de utilização da capacidade produtiva realizado, un é o nível ótimo de utilização da capacidade e $\varepsilon 1$ é um choque não sistemático; sendo $\beta 1$ positivo. A equação (19) seria a base do trade-off de curto prazo entre inflação e utilização e da curva de Phillips vertical no longo prazo. Qualquer desvio positivo do produto de seu nível potencial, ou da utilização realizada de seu nível ótimo, implica em aceleração inflacionária. O nível ótimo de utilização seria determinado por fatores reais e estaria fora de controle da política monetária. Logo, não há qualquer correlação de longo prazo entre moeda e atividade econômica. Por outro lado, seria assumida uma correlação entre aquelas variáveis no curto prazo, mediante uma curva IS. Tem-se:

$$
\mathrm{u}=\mathrm{u} 0-\beta 4 \mathrm{r}
$$

A equação (20) expressa a relação negativa entre investimento e taxa real de juros, sendo $r$ a taxa real de juros, $u 0$ um componente autônomo da demanda agregada e $\beta 4$ um parâmetro positivo. Dada a correlação entre taxa real de juros e utilização da capacidade, haveria a necessidade de se especificar uma regra de política monetária (KRIESLER; LAVOIE, 2007). Na Nova Síntese, o BC adota a taxa de juros como instrumento de políica, tal que:

$$
\mathrm{i}=\pi+\beta 5(\pi-\pi \mathrm{T})+\beta 6(\mathrm{u}-\mathrm{un})+\mathrm{rn}
$$

Em (21), vê-se um tipo de regra de Taylor. O BC ajusta a taxa nominal de juros com o objetivo de combater os desvios da inflação em relação à meta $(\pi \mathrm{T}) \mathrm{e}$ da utilização da capacidade em relação ao nível ótimo, sendo $i$ a taxa nominal de juros, rn a taxa natural de juros estimada pelo BC (Taylor, 1999); $\beta 5$ e $\beta 6$ são positivos. Pode-se reescrever a equação (21) em termos de gap da taxa real de juros. Já que $\mathrm{r}=\mathrm{i}-\pi$, tem-se:

$$
\mathrm{r}-\mathrm{rn}=\beta 7(\pi-\pi \mathrm{T})+\beta 8(\mathrm{u}-\mathrm{un})
$$

Na Nova Síntese, a equação (22) implica no fato de que sempre quando $\pi$ $=\pi \mathrm{T}$ e $\mathrm{u}=$ un, haverá $\mathrm{r}=\mathrm{rn}$; $\beta 7$ e $\beta 8$ são positivos. Para Galí e Gertler (2007), o $\mathrm{BC}$ deve perseguir $\mathrm{r}=\mathrm{rn}$ em todos os períodos, e como consequência a economia estará em seu estado estacionário, compatível com o equilíbrio dinâmico em um 
modelo de ciclos reais de negócios (GOODFRIEND; KING, 1997; CLARIDA; GALÍ; GERTLER, 1999). O único desafio para o BC seria localizar os valores naturais (de equilíbrio) da economia, que podem sofrer alterações consideráveis no tempo (GALÍ; GERTLER, 1999).

O problema com a equação (22) seria a possibilidade de uma má estimação da taxa natural de juros (TAYLOR, 1999). Se, por exemplo, a taxa natural estimada for maior que a verdadeira taxa natural de juros, a taxa de inflação de longo prazo será menor que a meta de inflação, ainda que haja a convergência da utilização da capacidade para seu nível ótimo. Neste caso, o BC precisa realizar uma nova estimação da taxa natural. Seguindo Setterfield (2005), Kriesler e Lavoie (2007) apresentam a regra de política da Nova Síntese em diferenças, como forma de se evitar o problema mencionado acima. Tem-se:

$$
\Delta r=\beta 7(\pi-\pi \mathrm{T})+\beta 8(u-u n)
$$

Ademais, substituindo (19) em (23), e fazendo o choque igual a zero, tem-se:

$$
\Delta r=\beta 7(\pi-\pi \mathrm{T})+(\beta 8 / \beta 1)(\Delta \pi)
$$

Pela equação (24), o BC responde elevando a taxa real de juros quando há aumento do nível e da variação da taxa inflacionária. Há, portanto, uma punição maior face a situações de pressões inflacionárias (KRIESLER; LAVOIE, 2007).

Uma crítica, feita por Kriesler e Lavoie (2007), ao modelo padrão desenvolvido acima, seria a de que não haveria necessariamente uma aceleração da inflação na presença de aumentos da utilização da capacidade, ideia esta próxima dos resultados de Arestis e Sawyer (2008). Existiria uma ampla gama de níveis de utilização para a qual não estariam presentes rendimentos decrescentes, de maneira que os produtores não seriam forçados a remarcar preços face a qualquer aumento da utilização (LAVOIE, 2004). Mecanismos de coordenação institucional também permitiriam maior emprego dos recursos sem que houvesse necessariamente pressões no preço dos mesmos. Um exemplo seria a coordenação entre trabalhadores, o que tornaria sem sentido a unicidade da NAIRU (HEIN, 2002). Na presença de competição imperfeita, a curva de custos médios em formato de U perde aderência empírica. É possível que empresas busquem operar na faixa em que os custos médios caem com o aumento da produção, dada a existência de economias de escala. Neste caso, não haveria a relação positiva entre gap do produto e inflação sugerida pela curva de Phillips novo-keynesiana (ARESTIS; SAWYER, 2008).

Logo, Kriesler e Lavoie (2007) apresentam uma modificação pós-keynesiana da curva de Phillips. Essa modificação daria conta da existência de um intervalo de variações na utilização da capacidade dentro do qual não haveria impactos inflacionários, seja porque os preços dos insumos não sofreriam pressões, seja porque a produtividade do trabalho seria constante. A troca entre inflação e desemprego só seria verificada para níveis muito baixos de utilização da capacidade, ou para 
níveis muito altos. $\mathrm{O}$ intervalo entre esses dois extremos seria amplo e a parte relevante de análise, em que mudanças de atividade não levariam a maiores ou menores taxas de inflação. Logo, ao invés de uma curva de Phillips positivamente inclinada no curto prazo dada por (19), haveria uma curva de Phillips pós-keynesiana horizontal no curto prazo, dada por:

$$
\pi=\beta 11(u-u m)+\beta 12(u-u f c)+\pi n
$$

Em que ufc é a capacidade plena de utilização, um é uma taxa mínima de utilização, abaixo da qual a taxa de inflação se reduz e $\pi n$ é a taxa de inflação compatível com o intervalo normal de utilização, sujeito a choques de oferta. Ademais:

$$
\begin{aligned}
& \beta 11=0 \text { para } u \geq u m \text { e } \beta 11>0 \text { para } u<u m ; \\
& \beta 12=0 \text { para } u \leq u f c \text { e } \beta 12>0 \text { para } u>u f c .
\end{aligned}
$$

De (25), (25a) e (25b) segue que para um $\leq u \leq u f c$, haverá $\pi=\pi n$ e $\Delta \pi=0$. Logo, estando o produto abaixo de seu nível máximo, a política monetária pode ser expansionista sem que haja pressões sobre a inflação, enquanto $u<u f c$. Como resultado, essa especificação pós-keynesiana da curva de Phillips não leva a uma verticalização da mesma no longo prazo, como o faz a especificação da Nova Síntese. Como, na primeira, mudanças de produto no curto prazo, dentro do intervalo relevante, não geram aumento da taxa de inflação, não existem impactos sobre as expectativas inflacionárias, pelo que no longo prazo também haverá uma curva horizontal para o intervalo relevante (KRIESLER; LAVOIE, 2007). Essa especificação teórica da Curva de Phillips está em consonância com as evidências empíricas encontradas por Filardo (1998), que mostra um intervalo aproximadamente entre 1 ponto percentual abaixo e acima do gap do produto, dentro do qual a inflação não sofreria mudanças.

Ademais, na concepção pós-keynesiana, em casos de pressões inflacionárias, a elevação da taxa de juros pelo $\mathrm{BC}$ pode aumentar os custos financeiros dos agentes, elevando, ao invés de reduzir, a taxa inflacionária, através do que se convencionou chamar de efeito Wright Patman (KRIESLER; LAVOIE, 2007); de fato, para os pós-keynesianos a inflação possui forte e sistemático componente de custos. Analisando essa visão, Mollo (2004, p.336) afirma que

Ao tratar dos aumentos de custos que provocam inflação, os pós-keynesianos se referem, além dos aumentos salariais, a aumentos das margens de lucro, rendimentos decrescentes, custos dos produtos importados e choques de oferta. A inflação pode também ser de demanda, mas esse é um caso menos provável porque só ocorre após o pleno emprego.

Sob essa perspectiva, uma vez que para a faixa relevante de produção não haveria pressões de custos que impusessem variações da taxa inflacionária, e dado que variações inflacionárias são um fato estilizado das economias - ou seja, e dado 
que a taxa de inflação possui variância maior que zero como uma evidência empírica universal; logo, quais seriam os fatores determinando as flutuações sistemáticas da taxa inflacionária? A escola pós-keynesiana vai conceber os fatores estruturalistas, tais como remarcação de mark-up e barganha salarial, como sendo os componentes que influenciam as mudanças sistemáticas na inflação, e que não estão necessariamente correlacionados com o nível de atividade econômica. Em outras palavras, pressões altistas de preços podem emergir inclusive sob condições recessivas na economia, caso a fonte inflacionária esteja em uma busca por recuperação de poder de compra ou de participação na renda por parte de empresas e trabalhadores. Smithin (2009), por exemplo, analisa a determinação da taxa de inflação de longo prazo, em um modelo com características kaleckianas e póskeynesianas, a partir de uma equação de mark-up, tal como:

$$
\mathrm{P}=\mathrm{kWN} / \mathrm{Y}
$$

Em que P é o nível geral de preços, k é o mark-up médio, $\mathrm{W}$ o salário nominal médio, $\mathrm{N}$ o nível de emprego e Y o PIB real. Em seguida, Smithin (op. cit.) descreve o processo de formação do salário nominal como:

$$
\mathrm{W}=\mathrm{P}_{-1}(\mathrm{~W} / \mathrm{P})^{*}
$$

Sendo P-1 o nível geral de preços no período t-1, e (W/P)* o salário real médio desejado ("a real wage target") pela classe trabalhadora. O autor substitui (27) em (26), chegando em uma nova equação para o nível geral de preços, tal que:

$$
\mathrm{P}=\mathrm{k}\left[\mathrm{P}_{-1}(\mathrm{~W} / \mathrm{P})^{*}\right] \mathrm{N} / \mathrm{Y}
$$

Logo, os preços são determinados por um processo de barganha ou conflito estrutural, em que tanto o mark-up médio quanto a meta de salário real influenciam a dinâmica inflacionária. Smithin (2009) coloca a equação (28) em logaritmo, fazendo:

$$
\mathrm{p}=\mathrm{p}_{0}+\mathrm{w}^{*}-\mathrm{a}
$$

Tal que $\mathrm{p}=\ln \mathrm{P}-\ln \mathrm{P}_{-1} ; \mathrm{p}_{0}=\ln \mathrm{k} ; \mathrm{w}^{*}=\ln (\mathrm{W} / \mathrm{P})^{*} ; \mathrm{a}=\ln (\mathrm{Y} / \mathrm{P})$. O autor ainda especifica uma equação para a meta de salário real:

$$
\mathrm{w}^{*}=\mathrm{w}_{0}+\eta \mathrm{y}_{-1}
$$

Assim, a dinâmica do salário real médio desejado pela classe trabalhadora depende basicamente da taxa de crescimento do PIB no período passado $\left(\mathrm{y}_{-1}\right)$, sendo $\eta>0$, e $\mathrm{w}_{0}$ uma condição inicial ou uma base de salário real (base real wage rate). Finalmente, substituindo (30) em (29), chega-se a:

$$
\mathrm{p}=\mathrm{p}_{\mathrm{o}}+\mathrm{w}_{\mathrm{o}}+\eta \mathrm{y}_{-1}-\mathrm{a}
$$

Smithin (2009), destarte, explica uma elevação de preços na economia como sendo causada por aumentos nos mark-ups, ou na base de salário real, ou ainda no crescimento do PIB em t-1, ou por reduções na produtividade. Se- 
melhantemente, Oreiro e Neves (2009, p. 472), ao analisarem os fenômenos de distribuição, crescimento e metas para inflação num modelo pós-keynesiano, consideram a inflação

[...] que a inflação é originada fundamentalmente por pressões de custo na economia, ao invés de ser causada por pressões de demanda. Com efeito, a inflação é um sintoma da existência de um conflito entre capitalistas e trabalhadores a respeito da fração da renda agregada a ser apropriada por cada um dos grupos sociais em consideração.

De fato, pode-se considerar a inflação nesses modelos enraizados nas escolas pós-keynesianas e pós-kaleckianas como um fenômeno que envolve necessariamente a dimensão da distribuição de renda entre os diferentes atores que participam do processo produtivo.

A inflação é sempre, nesse caso, originada em uma ação ou em uma reação por parte dos agentes econômicos; ação deliberada quando os mesmos querem aumentar suas participações relativas no produto e na renda, independentemente das condições de mercado ou da atividade econômica corrente, conduzindo a economia a mudanças nas metas de salário real e/ou de mark-up - neste caso, as mudanças nessas variáveis são exógenas e eventualmente sem qualquer justificativa palpável para tanto; reação quando há um processo de demanda e atividade que pressiona os custos produtivos, alterando as participações relativas dos diferentes setores e agentes na renda, e levando-os a uma busca por recuperação das perdas - aqui, as mudanças nas referidas metas são endógenas. Mesmo neste caso, cumpre dizer, a inflação possui inevitavelmente uma implicação distributiva. Ela, a inflação, é efeito e causa de alterações distributivas. No entanto, o fato de mudanças nos preços serem ocorrências legitimadas e institucionalizadas, a inflação é uma solução "civilizada" para conflitos distributivos, os quais seriam resolvidos por meios menos sutis se nossa sociedade vivesse em plena barbárie.

\section{Com base em que objetivols) e reações a política monetária deve ser conduzida?}

\subsection{Os objetivos e reações de política monetária na tradição da Nova Síntese}

A política monetária, tal como vista pela Nova Síntese Neoclássica, está apoiada fundamentalmente nos resultados teóricos de trabalhos como Barro e Gordon (1983), Kydland e Prescott (1977) e Calvo (1978). Para estes, políticas que tenham como objetivo expandir a produção para além das restrições impostas pelo lado da oferta são fadadas a contaminarem a economia com taxas de inflação 
excessivas, sem quaisquer benefícios em termos de atividade econômica no longo prazo.

Por outro lado, as rigidezes ou fricções de preços e mercados no curto prazo, na linha de Blinder e Mankiw (1984) e Mankiw (1985), fornecem algum poder transitório para políticas de administração de demanda. Assim, ao menos para o curto prazo, a Nova Síntese vê um objetivo contra-cíclico para a política monetária, porém concebendo as restrições impostas pelo produto potencial como estando fora da zona de influência dos Bancos Centrais. Esses objetivos, nos modelos da Nova Síntese, são expressos pelas chamadas funções objetivo ou "funções perda social" (social loss function). De fato, aceita a especificação de uma dada função perda social, e em especial a forma com que são determinados os valores de longo prazo da economia, condiciona-se a estratégia e os resultados da política monetária face aos choques percebidos.

Tal como em Svensson (1997), pode-se apresentar duas funções objetivo do $\mathrm{BC}$, uma válida para uma análise de longo prazo em que o objetivo seja unicamente estabilizar a taxa de inflação, no âmbito de um regime de metas para inflação por exemplo; a segunda seria válida para uma análise de curto prazo, em que há objetivos adicionais de política, como a estabilização do produto ou do emprego, que criam alguma forma de trade-off entre os objetivos do $\mathrm{BC}$, sob certas condições especiais, como sob choques de oferta. Sejam:

$$
\begin{gathered}
\mathrm{L}=\left(\pi-\pi_{\mathrm{o}}\right)^{2} \\
\mathrm{~L}=\left(\pi-\pi_{\mathrm{o}}\right)^{2}+\lambda \mathrm{y}^{2}
\end{gathered}
$$

A função perda (32) é representativa de uma análise de longo prazo na Nova Síntese neoclássica: o Banco Central se atém ao que realmente ele poderia fazer no longo prazo, ou seja, atuar sobre a dimensão nominal da economia, em particular estabilizando a inflação em torno de uma meta adotada $\left(\pi_{\mathrm{o}}\right)$. Desvios em torno dessa meta são percebidos como perdas sociais, e devem ser evitados. Logo, o uso de uma resposta de taxa de juros pelo Banco Central está condicionado ao objetivo de minimizar a função perda, minimizando as flutuações da inflação em torno da meta. Por outro lado, a função perda (33) representa o caso em que o $\mathrm{BC}$ possui um único objetivo de longo prazo - estabilizar a inflação -, porém o objetivo de estabilizar a inflação e o produto no curto prazo, em torno da meta de inflação e do produto potencial, respectivamente. Nas palavras de Svensson (1997, p. 1131, grifo nosso):

More specifically, consider a situation when there is a long-run inflation target, but no long-run output target (other than the natural rate of output), since monetary policy cannot affect output in the long run. In the short run, suppose the goal of monetary policy is to stabilize both inflation and output around the long-run inflation target and natural output rate, respectively. Thus, in the goals for monetary 


\section{policy, there is a symmetry between inflation and output in the short run, but not in the long run.}

Na função (33), a constante $\lambda$, maior que zero, dá o peso social da estabilização do produto. Assim, quanto maior o valor de $\lambda$, mais gradual será a resposta do BC e a convergência da inflação para meta após um choque, visto que maior será a intenção de se evitarem flutuações do produto - o que ocorre especialmente sob choques de oferta. Essa argumentação está muito presente nos trabalhos que seguem a linha de Svensson (1997) e Ball (1999). Na citação anterior, coloca-se em negrito aquele primeiro trecho para que se destaque a forma com que a Nova Síntese concebe o poder de atuação do BC no longo prazo, o qual se limitaria a controlar a inflação. O segundo termo em negrito é complementar, destacando o papel contra-cíclico do BC como limitado ao curto prazo. Ora, essa concepção de objetivos, perdas e respostas dos Bancos Centrais frente aos choques experimentados pelas economias está intimamente ligada ao que foi tratado na segunda seção deste trabalho, a saber, à natureza e restrição do processo de produção e de crescimento do produto no longo prazo.

Ademais, a tradição recente de análises de política monetária, na Nova Síntese, também lida com outros objetivos adicionais de política monetária, que criam trade-offs transitórios entre os objetivos expressos nas funções perdas. Estabilização de câmbio em economias abertas e estabilização ou suavização (smoothing) de taxas de juros são exemplos típicos. Contudo, as razões e justificativas para flexibilização da política monetária, e em particular do regime de metas para inflação, tais como apresentadas pela Nova Síntese, estão condicionadas sempre à concepção sobre a natureza estrutural das relações entre as variáveis econômicas relevantes. Logo, uma aparente flexibilização do regime, por meio de objetivos adicionais de política, pode mascarar uma real limitação que se dá à eficácia de política monetária sobre variáveis específicas em períodos mais longos. Isso é visível no caso da "flexibilização" do regime tal como proposto pela função perda (33) acima. Estabilizar o produto no curto prazo não muda o fato de que o BC, nessa análise mainstream, é visto como incapaz de atuar sobre a atividade econômica no longo prazo.

De fato, uma vez especificadas as equações estruturais do modelo e a função perda social adotada, pode-se chegar endogenamente a uma regra de reação para $\mathrm{o} \mathrm{BC}$, quando frente a choques que façam divergir os valores relevantes das metas estipuladas. Essa regra de instrumento ou de resposta também pode ser especificada de maneira ad hoc, tal como uma regra de Taylor simples, que desempenha papel relativamente eficaz nos modelos convencionais de inflation targeting.

Ademais, a crise financeira recente fez ressurgir com mais força o debate sobre os múltiplos objetivos/instrumentos com os quais os bancos centrais devem 
e/ou podem trabalhar. Embora esse debate pós-crise específico não seja o foco deste trabalho, é oportuno ressaltar que objetivos de estabilização dos mercados e preços financeiros e cambiais, via supervisão e fiscalização, compõem um conjunto de metas que vai para além da mera estabilização de preços ao consumidor e da atividade econômica de curto prazo (BLANCHARD; DELL'ARICCIA; MAURO, 2010). Da mesma maneira, a política monetária pode fazer melhor uso de medidas macro-prudenciais e de exigências que, em conjunto com a tradicional política de juros, criem uma dinâmica patrimonial das instituições financeiras mais consistente com os objetivos traçados.

\subsection{Objetivos e regras de política monetária nos pós-keynesianos}

A principal divergência dos pós-keynesianos para com a Nova Síntese, no que diz respeito aos objetivos norteadores de política monetária, concentra-se na possibilidade do BC possuir papel decisivo para alterar as condições estruturais da atividade econômica, por meio de efeitos reais de longo prazo. Obviamente, essa divergência apoia-se na controvérsia sobre a neutralidade da moeda no longo prazo. Nas palavras de Carvalho (2005, p. 334),

O regime de metas inflacionárias se apoia na proposição de que o impacto real da política monetária é efêmero, na melhor das hipóteses. Como argumentado aqui, isto é um erro, decorrente da visão limitada que se tem da moeda apenas como meio de pagamento e da política monetária como um simples regulador da quantidade de moeda em circulação.

Para Carvalho (2005) a teoria convencional limita o debate sobre metas de inflação, por exemplo, pois supõe que a política monetária não tem efeitos permanentes sobre a esfera real da economia. Para os modelos ortodoxos de Inflation Targeting, a atividade econômica é determinada no longo prazo pelo estoque de recursos produtivos, pelas preferências, pela tecnologia e pelo comportamento "racional" dos agentes, não havendo correlação entre moeda e produto potencial. Por sua vez, nas palavras de Sicsú (2002, p. 24):

Os defensores da adoção de metas de inflação acreditam que a política monetária não é um instrumento que pode estimular o investimento e, consequentemente, reduzir o desemprego. Apóiam suas crenças na hipótese da existência da taxa natural de desemprego, na curva expectacional de Phillips e no chamado viés inflacionário. Postulam que uma política monetária que aumente a liquidez da economia (e/ou reduza os juros) objetivando estimular o crescimento somente pode causar efeitos reais passageiros e efeitos inflacionários permanentes - tal como defendem Robert Lucas, Robert Barro e David Gordon em inúmeros trabalhos. 
É com base nessas premissas que a Nova Síntese estabelece um papel importante para as regras ótimas de política monetária, que em grande medida se assemelham à regra de Taylor padrão. Trabalhos como Ball (1999), Clarida, Galí e Gertler (1999) e Galí e Gertler (2007), dentre vários outros, propõem uma regra de instrumento de política monetária que ajusta a taxa de juros de curto termo em função da dinâmica corrente e/ou esperada da taxa de inflação e da atividade econômica, contudo sempre considerando o produto potencial ou a taxa potencial de crescimento do produto como variáveis de estado, ou seja, restrições reais impostas ao BC e fora de seu controle.

Face à grande literatura teórica e empírica mainstream sobre o tema das regras de política monetária, os pós-keynesianos teriam, aparentemente, poucas contribuições. Esta é a impressão de Palley (2006, p. 86-87):

The recognition that monetary policy should operate through interest rates rather than money supply targets leaves open the question of how interest rates should be set. Whereas the mainstream literature on this subject is extensive, Post Keynesians have had little to say formally.

Obviamente não se trata aqui de comparar exaustivamente o tamanho e o peso das contribuições das duas correntes de pensamento (Novo-síntese e Póskeynesiana); o fato é que recentemente algumas abordagens pós-keynesianas têm tratado do tema sobre regras de política monetária. Por exemplo, Fontana e Palácio-Vera (2007) propõem uma abordagem oportunística flexível (flexible opportunistic approach) para a política monetária, cuja premissa básica é a existência de path-dependence na determinação do produto potencial e os efeitos de longo prazo da política monetária sobre o mesmo. Nessa abordagem, o principal objetivo do Banco Central ainda é o de manter a estabilidade de preços no longo prazo e, neste sentido, assemelha-se à abordagem convencional. No entanto, as respostas propostas para a taxa real de juros face à dinâmica inflacionária são diferentes em comparação com as proposições mainstream, e isto se deve basicamente à premissa de efeitos reais de longo prazo a partir da política monetária.

No caso de um contexto de pressão inflacionária baixa, ou seja, quando a taxa de inflação está acima da meta de longo prazo, porém abaixo do limite superior estabelecido pelo Banco Central (BC), este deveria manter constante a taxa real de juros, ao contrário do que faria, segundo os autores, o $\mathrm{BC}$ convencional - que aumentaria a taxa real de juros. Desta maneira, o BC reduziria as chances de uma recessão induzida pela política monetária (FONTANA; PALACIO-VERA, 2007).

Ademais, os autores propõem que, quando a taxa de inflação se encontre abaixo da meta de longo prazo ou num nível equivalente à meta, o BC oportunístico flexível deveria reduzir a taxa real de juros, diferentemente do $\mathrm{BC}$ convencional, que, segundo os autores, iria manter a taxa real de juros constante ou aumentá-la. 
A regra de política proposta por e Fontana e Palácio-Vera (2007), portanto, tomaria vantagem dos impactos de longo prazo da política monetária sobre o produto potencial, utilizando-os para estimular maiores níveis de produto potencial com estabilidade de preços. Esta estabilidade, por sua vez, também seria viabilizada pelos próprios efeitos dos juros sobre a capacidade de produção. Assim, para Fontana e Palácio-Vera (2007, p. 89):

In other words, in the presence of sources of path dependency, the decision of the $\mathrm{CB}$ to stimulate aggregate demand not only increases the current level of output and employment but, importantly, it also changes the underlying economic relationships such as to allow the economy to produce permanently at higher levels of output and employment without engendering inflationary pressures. In other words, the $C B$ has lowered the NAIRU (non-accelerating inflation rate of unemployment).

Atesoglu (2007), por sua vez, propõe uma regra de política monetária que balize as decisões do Banco Central a partir do conceito e da estimação de uma taxa neutra de juros, ou seja, a taxa de juros que corresponde a uma situação de pleno emprego. Neste caso, a política monetária deveria perseguir a taxa nominal de juros que permita uma condição de pleno emprego com estabilidade de preços, dada a estimativa da taxa neutra de juros. Obviamente que esta estimativa está imersa em dificuldades técnicas assim como também estão as estimativas em torno do produto potencial ou da NAIRU na literatura novo-síntese. A grande diferença em relação ao pensamento desta última, entretanto, é que para Atesoglu (2007) o BC pode fazer política de juros com o intuito básico de promover o pleno emprego, não apenas no curto, mas também no longo prazo.

Palley (2006) também propõe uma regra de política monetária, balizada pelo que chama de Taxa de Desemprego Mínima de Inflação (MURI) (no inglês - Minimum Unemployment Rate of Inflation), que é a taxa de desemprego mínima que se pode alcançar por meio de incrementos na taxa de inflação, a qual é vista por Palley como um mecanismo para o ajuste do mercado de trabalho. Adota-se a hipótese de que aumentos da taxa de inflação são acompanhados de reduções da taxa de desemprego, porém isto ocorreria apenas até certo valor crítico da inflação, acima do qual novas elevações da mesma seriam acompanhadas de elevações também da taxa de desemprego. Trata-se de uma ruptura com a curva de Phillips mainstream.

Num primeiro caso, quando a taxa de inflação está abaixo do valor crítico - e a taxa de desemprego acima da MURI - os trabalhadores, em especial em indústrias enfraquecidas, aceitariam diminuições nos salários reais por conta de mais inflação, pelo que haveria correlação negativa entre inflação e desemprego; no entanto, num segundo caso, quando a taxa de inflação for elevada acima da taxa crítica, os trabalhadores rejeitariam novas perdas reais, pelo que haveria correla- 
ção positiva entre inflação e desemprego. Assim, a MURI corresponde a uma taxa de inflação ótima, ou seja, a taxa de inflação consistente com a taxa de desemprego mínima. O BC pode, neste caso, fazer política monetária com vistas ao alcance da MURI, a partir de ajustes na taxa básica de juros. Seja uma formalização deste pensamento:

$$
r_{t}=\alpha\left(P_{t}-P^{*}\right)
$$

Sendo $r_{t}$ o desvio entre a taxa real de juros de curto prazo corrente e a taxa real consistente com o pleno emprego ou com a MURI - i.e. a taxa de juros neutra em Atesoglu (2007); $\mathrm{P}_{\mathrm{t}}$ a taxa de inflação corrente e $\mathrm{P}^{*}$ a taxa de inflação (meta) consistente com a MURI. Obviamente, trata-se de estimar P* (e a MURI), um problema não menos espinhoso do que o de estimar uma variável de produto potencial ou mesmo de NAIRU.

De fato, a proposta de Palley (2006) pode ser vista como um caso especial de inflation targeting, qual seja, quando valores de $\mathrm{P}$ acima de $\mathrm{P}^{*}\left(\mathrm{P}>\mathrm{P}^{*}\right)$ são acompanhados necessariamente de aumento da taxa de desemprego, potencializando as perdas sociais. No caso mainstream, por outro lado, com base na curva de Phillips padrão, desvios inflacionários positivos $\left(\mathrm{P}>\mathrm{P}^{*}\right)$ podem ser acompanhados de reduções na taxa de desemprego, o que pode gerar benefícios sociais de curto prazo. Outra questão que pode ser explorada é a possibilidade de se gerar, por meio da política monetária, estímulos a uma redução da MURI, o que caracterizaria um processo de endogenia da MURI pelo lado da demanda, embora esse aspecto não seja bem analisado e formalizado por Palley (2006).

Uma análise também recente e original que propõe uma regra de instrumento heterodoxa está em Moreira (2009, 2011). Parte-se da ideia de endogenia do produto potencial pelo lado da demanda, fundamentada nos conceitos de não neutralidade da moeda no longo prazo e de efeito acelerador do investimento, o que configura um processo de histerese e path-dependence na determinação dos resultados de longo prazo. $\mathrm{O}$ autor apresenta uma função perda social expandida, em que é incorporado um tipo de custo social de oportunidade. Seja:

$$
\mathrm{C}_{\mathrm{y}}=\left\{\mathrm{E}\left[\left(\mathrm{Y}_{\mathrm{t}}^{\mathrm{p}}\right)^{\mathrm{f}}\right]-\left(\mathrm{Y}_{\mathrm{t}}^{\mathrm{p}}\right)^{\mathrm{s}}\right\}
$$

Assim, esse custo de oportunidade, associado a um regime de política monetária convencional (ortodoxo) poderia ser expresso por $\mathrm{C}_{\mathrm{y}}$ (custo social de oportunidade), em que $\mathrm{E}\left[\left(\mathrm{Y}_{\mathrm{t}}^{\mathrm{p}}\right)^{\mathrm{f}}\right]$ é a esperança para o produto potencial em t que seria observado se o $\mathrm{BC}$ aplicasse uma política de juros heterodoxa e $\left(\mathrm{Y}_{\mathrm{p}}^{\mathrm{p}}\right)^{\mathrm{s}}$ é o produto potencial efetivo sob regime convencional ${ }^{4}$. Por política de juros heterodoxa, Moreira (2009) quer dizer uma resposta de taxa básica de juros que leve em conta o

4 Está implícita a suposição de que o regime ortodoxo criará, ao longo do tempo, uma dinâmica do produto potencial, na média ao menos, inferior à dinâmica que seria observada sob um regime não-convencional de política monetária. Assim, em geral $\left\{\mathrm{E}\left[\left(\mathrm{Y}_{\mathrm{t}}^{\mathrm{p}}\right)^{\mathrm{f}}\right]>\left(\mathrm{Y}_{\mathrm{t}}^{\mathrm{p}}\right)^{\mathrm{s}}\right\}$ e $\mathrm{C}_{\mathrm{y}}>0$. 
fato de que haverá impactos reais de longo prazo, através da endogenia do produto potencial pela demanda. A função perda social seria então:

$$
\mathrm{L}_{\mathrm{t}}=\mathrm{j}_{1}\left(\mathrm{Y}_{\mathrm{t}}-\mathrm{Y}^{\mathrm{p}}\right)^{2}+\mathrm{j}_{2}\left(\Pi_{\mathrm{t}}-\Pi^{\mathrm{n}}\right)^{2}+\mathrm{j}_{3}\left(\mathrm{C}_{\mathrm{y}}\right)
$$

A função perda social (36) acima mostra que o custo de oportunidade representa um tipo de perda social, que ocorre quando o Banco Central combate os choques sem considerar a endogenia do produto potencial, impondo uma trajetória do nível de produto potencial aquém daquela que poderia ser observada. Portanto, quando a autoridade monetária age de forma conservadora em extremo, e a partir de um modelo mal especificado 5 , a sociedade perde a oportunidade de contar com um produto potencial melhor ajustado às flutuações da demanda e da renda; em outras palavras, baseando-se em um modelo teórico que concebe a dinâmica do estoque de capital fixo como sendo não correlacionado com as variações observadas no campo monetário e dos dispêndios, perde-se a oportunidade de se regular as flutuações no nível de atividade econômica e na inflação com o objetivo de se gerar uma melhor dinâmica do produto potencial da economia.

$\mathrm{O}$ ajustamento do produto potencial ao produto efetivo implica, por exemplo, no caso de um choque positivo de demanda - e do consequente gap positivo do produto -, uma alteração (elevação) mais suave da taxa de juros, e isto porque haverá uma parte do choque que será eliminada endogenamente, via efeito acelerador e de variação do produto potencial.

Para Moreira (2009) a minimização desse custo social de oportunidade $\left(\mathrm{C}_{\mathrm{y}}\right)$ poderia ser obtida via uma regra de instrumento do BC que fosse calibrada para variações esperadas do produto potencial, as quais decorrem das flutuações da demanda e do produto efetivo no curto prazo - o que configura um caso de histerese, tal como em Lavoie (2006).

Moreira (2011), uma síntese de Moreira (2009), propõe uma regra de instrumento do $\mathrm{BC}$ frente a choques de demanda em particular. Mostra-se que um "BC heterodoxo" - consciente da endogenia do produto potencial - reduz mais agressivamente a taxa real de juros diante de uma recessão, se comparado com um $\mathrm{BC}$ convencional; e eleva mais lentamente a taxa real de juros face a um choque positivo de demanda, também quando comparado com um BC ortodoxo. Essas diferenças são alcançadas por meio de uma formalização, qual seja:

$$
\mathrm{r}_{\mathrm{t}}=\mathrm{z}_{1} \pi_{\mathrm{t}}+\left(\mathrm{z}_{2}-\mathrm{kv}\right) \mathrm{y}_{\mathrm{t}}-\mathrm{ki}_{\mathrm{t}}+\mathrm{u}_{\mathrm{t}}
$$

A regra heterodoxa ou não convencional (37) é proposta para uma situação em que há choque positivo de demanda, ou seja, quando $\mathrm{y}_{\mathrm{t}}$ (gap do produto em $\mathrm{t}$ ) é maior que zero. Em que $r_{t}$ é o desvio entre a taxa real de juros de curto prazo em $t$ e a taxa real de juros tendencial, $\pi_{t}$ é o desvio entre a taxa de inflação em t e a meta

5 Um modelo que considere o produto potencial como sendo determinado de maneira independente dos movimentos da demanda e da renda. 
de inflação, $\mathrm{i}_{\mathrm{t}}$ é o desvio entre a taxa de investimento líquido (formação líquida de capital fixo/produto) em t e a taxa desejada; os parâmetros $z_{1}, z_{2}, k$ e v são todos positivos e $u_{t}$ é um choque com média zero e variância constante (white-noise shock).

Os desdobramentos da regra heterodoxa proposta em Moreira (2011) são melhor compreendidos se analisarmos em conjunto o que seria, na visão do autor, uma regra convencional:

$$
r_{t}=z_{1} \pi_{t}+z_{2} y_{t}+\varepsilon_{t}
$$

Em que as variáveis são as mesmas na regra (37), os coeficiente são positivos e $\varepsilon_{\mathrm{t}}$ é um choque de política (white-noise). Neste caso, quando $\mathrm{y}_{\mathrm{t}}>0$, tanto o $\mathrm{BC}$ convencional - por meio de (38) - quanto o $\mathrm{BC}$ não convencional - por meio de (37) - elevam a taxa real de juros. Contudo, o BC heterodoxo eleva a taxa real de juros em menor medida, mais parcimoniosamente, visto que $\left(\mathrm{z}_{2}-\mathrm{ku}\right)<\mathrm{z}_{2}$.

As diferenças entre (37) e (38), vale dizer, são geradas endogenamente pelo modelo proposto, através de uma função endogenia do produto potencial pela demanda e considerando a previsão de produto potencial futuro na regra de política monetária ${ }^{6}$. Interessante dizer que uma política monetária que leve em conta projeções futuras de crescimento e a endogenia de (estimativas de) produto potencial atende às sugestões de Barbosa-Filho (2009).

Adicionalmente, face a uma situação em que $y_{t}>0$, o autor argumenta que o $\mathrm{BC}$ deve calibrar a taxa real de juros, reduzindo-a quanto maior for a taxa de investimento líquido corrente face ao valor desejado, ou seja, quanto maior $\mathrm{i}_{\mathrm{t}}$, menor deveria ser $r_{t}$, dado $k$, uma vez que os novos investimentos líquidos induzidos, em meio ao choque positivo de demanda, criarão maior capacidade produtiva no futuro, permitindo o amortecimento das pressões inflacionárias correntes.

Por sua vez, quando a economia estivesse sob um choque negativo de demanda, o $\mathrm{BC}$ não convencional usaria a seguinte regra - também gerada endogenamente em Moreira (2009, 2011):

$$
r_{t}=z_{1} \pi_{t}+\left(z_{2}+k v\right) y_{t}+k i t+u_{2 t}
$$

As variáveis e parâmetros são os mesmos empregados em (37). A diferença é que quando $\mathrm{y}_{\mathrm{t}}<0$, sob choque negativo de demanda, o $\mathrm{BC}$ heterodoxo reduz a taxa real de juros mais agressivamente, se comparado com o que faz o $\mathrm{BC}$ convencional (38), visto que $\left(z_{2}+k v\right)>z_{2}$. Adicionalmente, com a queda de $i_{t}$ (investimentos líquidos em formação de capital) face ao choque negativo de demanda, $\mathrm{o}$ $\mathrm{BC}$ deveria potencializar a redução da taxa real de juros, com o objetivo de evitar ao máximo possível as perdas de produto potencial no futuro. Neste caso, enquanto diante de um choque positivo de demanda o $\mathrm{BC}$ eleva a taxa real de juros

6 As equações aqui são apresentadas apenas como ilustração do argumento. Não serão, por motivo de objetividade, analisadas todas as equações do modelo, nem seu encadeamento lógico. O leitor interessado pode conferir Moreira (2009, 2011). 
mais parcimoniosamente do que faz o BC convencional, face ao choque negativo a redução da taxa real é mais agressiva. Uma resposta não linear e com vistas à minimização do custo social de oportunidade na equação (36).

Tais resultados parecem corroborar a impressão de Carvalho (2009, on-line), ao analisar a resposta do Banco Central brasileiro diante da recessão causada pela crise financeira internacional recente:

A diretoria do Banco Central não se mostrou à altura das demandas da economia brasileira e ninguém se surpreendeu com isto, que afinal vem de longe. Surpreendente seria se agissem diferentemente. Com sua lentidão paquidérmica, o Banco Central age como aquele convidado encarregado de trazer a cerveja para a festa e chega quando todos já foram embora.

De certa forma, os trabalhos pós-keynesianos sobre o assunto mostram que uma política monetária convencional, baseada nas premissas de neutralidade da moeda e de taxa natural, e apoiada no uso de regras simples tipo Taylor, criam vieses e perdas econômicas. Nas palavras de Lima e Setterfield (2008, p. 435), “[...] that the more orthodox the policy blend becomes in a Post Keynesian economy, the more adverse are the consequences for macroeconomic stability and the viability of inflation targeting."

Neste caso, trata-se de adotar estratégias e políticas consistentes com as premissas de uma economia pós-keynesiana. O regime de metas de inflação, por exemplo, apenas daria um objetivo de política, entre outros possíveis. Haveria uma escolha relevante e política a ser feita, por outro lado, no que diz respeito ao arranjo institucional e à forma de se alcançar a meta de inflação. A escolha do valor da inflação a ser definido como meta, o tempo necessário para seu alcance, o peso dado a outros fatores de controle da política monetária - como atividade econômica de longo prazo e taxa de desemprego - e as restrições ao alcance da meta, são questões que dependeriam das premissas da teoria por trás do modelo balizador de política monetária.

\section{Considerações Finais}

Acredita-se que a prática da política monetária no mundo, bem como a prática de qualquer tipo de política pública, está permeada pelas impressões e resultados lançados pela teoria de cada momento. A despeito de controvérsias teóricas existentes acerca dos temas aqui tratados, há um conjunto de elementos e consensos relativos que dominam e contextualizam as decisões de política dos conselhos de diretores (monetary policymakers), seja no Brasil, seja em qualquer país que adote o receituário de estabilidade de preços como um dos pilares de política econômica. 
A chamada Nova Síntese Neoclássica, ao pegar carona na elegância formal, no apelo empírico acumulado pelos monetaristas dos anos 60 e 70, e na hegemonia científica e política dos modelos novo-clássicos e novo-keynesianos, estes mais recentes, vem ganhando papel crescente na condução efetiva de taxas de juros no mundo contemporâneo. Um exemplo disto é a crescente gama de países que adere ao regime de metas de inflação nas últimas duas décadas, regime este amplamente desenvolvido e sustentado pelas ideias da Nova Síntese.

Um exercício interessante para se examinar a convergência da prática de política de um dado $\mathrm{BC}$ na direção de uma ou outra corrente de pensamento seria por meio de uma análise sistemática de anúncios e ratificações feitos nos Relatórios de Inflação e Atas de Reuniões dos Conselhos de Política Monetária, como por exemplo, o COPOM no Brasil e o Federal Open Market Committee (FOMC) nos EUA. Embora de relevância empírica, tal exercício não caberia como foco neste trabalho, ficando para outro espaço de análise.

Finalmente, os teóricos em política monetária, e os Bancos Centrais com a prática da mesma, precisam lidar com um leque de objetivos e instrumentos de política mais amplo e complexo, como demonstrou a recente crise financeira internacional. Em especial no que respeita ao papel de supervisão/fiscalização bancária, as autoridades monetárias têm de melhorar sua capacidade de monitoração e regulação sobre as decisões de captação e aplicação das instituições financeiras, a fim de que sejam minimizadas as chances de fragilização sistêmica.

Tomando como premissa o fato de que são as decisões patrimoniais das instituições financeiras, e bancárias em especial, por meio de operações e ativos cada vez mais fluidos, que condicionam a dinâmica dos meios de pagamento, da atividade econômica e dos preços de bens, serviços e ativos financeiros, os Bancos Centrais precisam refinar e potencializar seus métodos e instrumentos de controle/ estímulo sobre aquelas decisões.

Medidas macro-prudenciais ganham, portanto, papel de extrema relevância, complementando o conjunto de instrumentos, que vai para além do mero uso das taxas de juros de curto termo, embora estas ainda continuem com utilidade nas decisões dos monetary policymakers, em especial face às variações de curto prazo no gap do produto e nos desvios inflacionários; mas as medidas macro-prudenciais, tais como as exigências de capital, liquidez e margem para as instituições financeiras, devem ser utilizadas como forma de alcançar metas específicas de composição do produto, dos financiamentos e de preços de ativos financeiros, complementando os objetivos existentes de estabilidade dos preços ao consumidor e da atividade produtiva (BLANCHARD, DELL'ARICCIA; MAURO, 2010). 


\section{Referências}

ARESTIS, P.; SAWYER, M. The new consensus macroeconomics: an unreliable guide to policy. Revista Análise Econômica, Porto Alegre, ano 26, n. 50, p. 275-297, set. 2008.

ATESOGLU, H. S. The neutral rate of interest and a new monetary policy rule. Journal of Post Keynesian Economics, Armonk, v. 29, n. 4, p. 689-697, July 2007.

BALL, L. Efficient rules for monetary policy. International Finance, Washington, US, v. 2, n. 1 , p. 63-83, Apr.1999.

BARBOSA FILHO, N. H. Estimando e revisando o produto potencial do Brasil: uma análise do Filtro Hodrick-Prescott com Função de produção. In: GENTIL, D. L.; MESSENBERG, R. P. (Org.). Crescimento econômico: produto potencial e investimento. Rio de Janeiro: IPEA, 2009.

BARRO, R. J.; GORDON, D. B. A positive theory of monetary policy in a natural rate model. The Journal of Political Economy, Chicago, v. 91, n. 4, p. 589-610, Aug.1983.

BHADURI, A.; MARGLIN, S. Unemployment and the real wage: the economic basis for contesting political ideologies. Cambridge Journal of Economics, London, v. 14, n. 4, p. 375-393, Dec.1990.

BLANCHARD, O.; DELL'ARICCIA, G.; MAURO, P. Rethinking macroeconomic policy. IMF Staff Position Note, New York, Feb. 2010.

BLINDER, A. S.; MANKIW, N. G. Aggregation and stabilization policy in a multi-contract economy. Journal of Monetary Economics, Amsterdam, v. 13, n. 1, p.67-86, Jan. 1984.

BRAINARD, W. C. Uncertainty and the effectiveness of policy. The American Economic Review, Nashville, v. 57, n. 2, p. 411-425, May 1967.

CALVO, G. On the time consistency of optimal policy in a monetary economy. Econometrica, Chicago, v. 46, n. 6, p. 1411-1428, Nov. 1978.

CARVALHO, F. J. C. Uma contribuição ao debate em torno da eficácia da política monetária e algumas implicações para o caso do Brasil. Revista de Economia Política, São Paulo, v. 25, n. 4, p. 323-336, out./dez. 2005.

CARVAlHO, F. J. C. A crise e o papel de cada um. Carta Maior, São Paulo, 22 mar. 2009.

CLARIDA, R.; GALÍ, J.; GERTLER, M. The science of monetary policy: a new Keynesian perspective. Journal of Economic Literature, Nashville, v. 38, p. 1661-1707, Dec. 1999.

DUTT, A. K. Growth, distribution and uneven development. Cambridge: Cambridge University Press, 1990.

. On the long-run stability of capitalist economies: implications of a model of growth and distribution. In: E. Elgar, 1994. . (Org). New directions in analytical political economy. Aldershot:

FILARDO, A. J. New evidence on the output cost of fighting inflation. Federal Reserve Bank of Kansas City Quarterly Review, Kansas City, v. 64, n. 9, p. 33-61, Nov. 1998.

FONTANA, G.; PALACIO-VERA, A. Are long-run price stability and short-run output stabilization all that monetary policy can aim for? Metroeconomica, Oxford, v. 58, n. 2, p. 269-298, May 2007.

GALÍ, J.; GERTLER, M. Macroeconomic modeling for monetary policy evaluation. Journal of Economic Perspectives, Nashville, v. 21, n. 4, p. 25-46, Sept. 2007. 
GOODFRIEND, M.; KING, R. G. The new neoclassical synthesis and the role of monetary policy. In: BERNANKE, B.; ROTEMBERG, J. (Ed.). NBER Macroeconomics Annual. Cambridge: The MIT Press, 1997.

HEIN, E. Monetary policy and wage bargaining in the EMU: restrictive ECB policies, high unemployment, nominal wage restraint and inflation above the target. Banca del Lavoro Quarterly Review, v. 222, p. 299-337, Sept. 2002.

KALDOR, N. Alternative theories of distribution. Review of Economic Studies, Bristol, v. 23, n. 2, p. 83-100, Jan. 1955.

KALECKI, M. Theory of Economic Dynamics. Londres: Allen E Unwin, 1954.

Selected essays on the dynamics of the capitalist economy. Cambridge: Cambridge University Press, 1971.

KRIESLER, P.; LAVOIE, M. The new view on monetary policy: the new consensus and its post-keynesian critique. Review of Political Economy, London, v. 19, n. 3, p. 387-404, July 2007.

KYDLAND, F. E.; PRESCOTT, E. C. Rules Rather than discretion: the inconsistency of optimal plans. Journal of Political Economy, Chicago, v. 85, n. 3, p. 473-491, June 1977.

LAVOIE, M. The new consensus on monetary policy seen from a post-Keynesian perspective. LAVOIE, M.; SECCARECCIA, M. (Ed.). Central Banking in the modern world: alternative perspectives. Cheltenham: E. Elgar, 2004. p. 15-34.

LAVOIE, M. A post-Keynesian amendment to the New consensus on monetary policy. Metroeconomica, Oxford, v. 57, n. 2, p. 165-192, May 2006.

LEÓN-LEDESMA, M.A.; THIRLWALL, A. P. The endogeneity of the natural rate of growth. Cambridge Journal of Economics, London, v. 26, n. 4, p. 441-459, July 2002.

LIMA, G. T.; MEIRELLES, A. J. A. Macrodynamics of debt regimes, financial instability and growth. Cambridge Journal of Economics, London, v. 31, n. 4, p. 563-580, July 2007.

LIMA, G. T.; SETTERFIELD, M. Inflation targeting and macroeconomic stability in a Post Keynesian economy. Journal of Post Keynesian Economics, Armonk, v. 30, n. 3, p. 435-461, Apr. 2008.

LOPEZ, G. J. Michal Kalecki e a teoria da demanda efetiva. Revista de Economia Política, São Paulo, v. 6, n. 3, p. 58-68, jul./set. 1986.

MANKIW, N. G. Small menu costs and large business cycles: a macroeconomic model of monopoly. Quarterly Journal of Economics, Cambridge, v. 100 n. 2, p. 529-537, 1985.

McCaLLUM, B. T.; NELSON, E. Nominal income targeting in an open-economy optimizing model. Journal of Monetary Economics, Amsterdam, v. 43, n. 3, p. 553-578, June 1999.

MOLLO, M. L. R. Otodoxia e heterodoxia monetárias: a questão da neutralidade da moeda. Revista de Economia Política, São Paulo, v. 24, n. 3, p. 323-343, jul. 2004.

MOREIRA, R. R. Uma perspective heterodoxa para o regime de metas de inflação: a hipótese da endogenia do produto potencial pelo lado da demanda. Tese (Doutorado em Economia da Indústria e da Tecnologia) - Instituto de Economia, Universidade Federal do Rio de Janeiro, Rio de Janeiro, 2009.

Flexibility in an inflation targeting regime under demand shocks: the endogenous potential output from the demand side. Journal of European Economy, v. 10, Special Issue, p. 306-326, 2011. 
OREIRO, J. L. C.; NEVES, A. L. Crescimento, distribuição de renda e metas de inflação num modelo macrodinâmico pós-keynesiano. EconomiA, Brasília, v. 10, n. 2, p. 465-482, set./dez. 2009.

OREIRO, J. L. C.; ONO, F. H. Progresso tecnológico, distribuição de renda e utilização da capacidade produtiva: uma análise baseada em simulações computacionais. Economia, Niterói, v. 5, n. 1, p. 35-66, jan./jul. 2004.

OREIRO, J. L. C. Acumulação de capital, equilíbrios múltiplos e path-dependence: uma análise a partir de um modelo pós-keynesiano de crescimento endógeno. Estudos Econômicos, São Paulo, v. 31, n. 1, p. 167-203, jan./mar. 2001.

PALLEY, T. A post Keynesian framework for monetary policy: why interest rate operating procedures are not enough. In: GNOS, C.; ROCHON, L.P. (Ed.). Post Keynesian principles of policy. Cheltenham: E. Elgar, 2006.

PASINETTI, L. Rate of profit and income distribution in relation to the rate of economic growth. Review of Economic Studies, Bristol, v. 29, n. 4, p. 267-279, Oct. 1962.

ROBINSON, J. Essays in the Theory of Economic Growth. London: Macmillan, 1962.

ROWTHORN, R. Demand, real wages and economic growth. In: SAWYER, M. C. (Ed.). Postkeynesian economics. Cheltenham: E. Elgar, 1982.

Unemployment, wage bargaining and capital-labour substitution. Cambridge Journal of Economics, London, v. 23, n. 4, p. 413-425, July 1999.

SAWYER, M.C. The NAIRU, aggregate demand and investment. Metroeconomica, Oxford, v. 53, n.1, p. 66-94, Feb. 2002.

SETTERFIELD, M. Introduction: a dissenter's view of the development of growth theory and the importance of demand-led growth. In: (Ed.). The Economics of Demand-led Growth: challenging the supply-side vision of the long run. Cheltenham: E. Elgar, 2002. p. 1-16.

. Central banking, stability and macroeconomic outcomes: a comparison of new consensus and post-Keynesian monetary macroeconomics. In: LAVOIE, M.; SECCARECCIA, M. (Ed.). Central Banking in the modern world: alternative perspectives. Cheltenham: E. Elgar, 2005. p. 35-56.

SICSÚ, J. Teoria e evidências do regime de metas inflacionárias. Revista de Economia Política, São Paulo, v. 22, n. 1, p. 23-33, jan./mar. 2002.

SMITHIN, J. Teaching the new consensus model of "monetary monetary economics" from a critical perspective: pedagogical issues.In: FONTANA, G.; SETTERFIELD, M. (Ed.). Macroeconomic theory and macroeconomic pedagogy. London: Palgrave, 2009. p. 255-72.

SVENSSON, L. E. O. Inflation forecast targeting: implementing and monitoring inflation targets. European Economic Review, Amsterdam, v. 41, n. 6, p. 1111-1146, June 1997.

TAYLOR, J. B. Monetary policy guidelines for employment and inflation stability. In: SOLOW, R.M.; TAYLOR, J.B. (Ed.). Inflation, unemployment, and monetary policy. Cambridge: The MIT Press, 1999. p. 29-54.

WALSH, C. E. Monetary theory and policy. $2^{\text {nd }}$ ed. Cambridge: The MIT Press, 2003.

Recebido em: 13/09/2010.

Aceito em: 15/07/2011. 